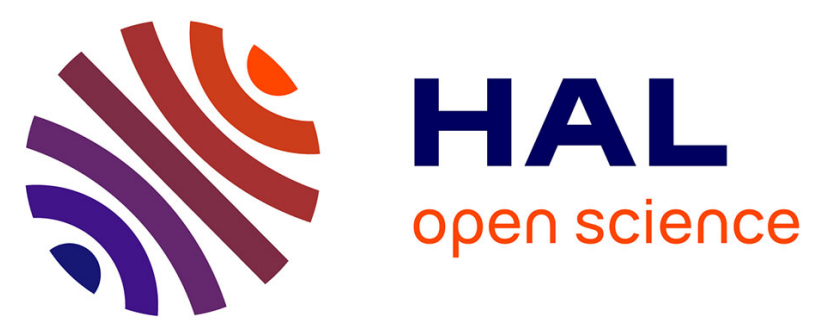

\title{
Effect of loading on the nature of the REE-humate complexes as determined by Yb3+ and Sm3+ LIII-edge EXAFS analysis
}

Remi Marsac, Mélanie Davranche, Nicolas Briant, Guillaume Morin, Yoshio Takahashi, Gérard Gruau, Aline Dia

\section{To cite this version:}

Remi Marsac, Mélanie Davranche, Nicolas Briant, Guillaume Morin, Yoshio Takahashi, et al.. Effect of loading on the nature of the REE-humate complexes as determined by $\mathrm{Yb} 3+$ and Sm3+ LIIIedge EXAFS analysis. Chemical Geology, 2015, 396, pp.218-227. 10.1016/j.chemgeo.2014.12.024 . insu-01111992

\section{HAL Id: insu-01111992 \\ https://hal-insu.archives-ouvertes.fr/insu-01111992}

Submitted on 4 Feb 2015

HAL is a multi-disciplinary open access archive for the deposit and dissemination of scientific research documents, whether they are published or not. The documents may come from teaching and research institutions in France or abroad, or from public or private research centers.
L'archive ouverte pluridisciplinaire HAL, est destinée au dépôt et à la diffusion de documents scientifiques de niveau recherche, publiés ou non, émanant des établissements d'enseignement et de recherche français ou étrangers, des laboratoires publics ou privés. 


\section{Effect of loading on the nature of the REE-humate complexes as}

\section{determined by $\mathrm{Yb}^{3+}$ and $\mathrm{Sm}^{3+} \mathrm{L}_{\text {III }}$ edge EXAFS analysis.}

Rémi Marsac ${ }^{1}$, Mélanie Davranche ${ }^{1 *}$, Nicolas Briant ${ }^{1}$, Guillaume Morin ${ }^{2}$, Yoshio Takahashi ${ }^{3}$, Gérard Gruau ${ }^{1}$, Aline Dia ${ }^{1}$

1. Géosciences Rennes - UMR CNRS 6118, Université Rennes 1 - Campus de Beaulieu, 35042 Rennes Cedex, France

2. Institut de Minéralogie, de Physique des Matériaux et de Cosmochimie, IMPMC, UMR CNRS 7590 Université Pierre et Marie Curie / Paris 6 - MNHN - IRD, Campus Jussieu, 4 place Jussieu, 75252 Paris Cedex 05, France.

3. Earth and Planetary Systems Science, Graduate School of Science, Hiroshima University, 1-3-1, Kagamiyama, Higashi-Hiroshima, Hiroshima 739-8526, Japan.

\section{Corresponding Author}

*Phone: +33 2 23235769, fax: +332 23235787, e-mail: melanie.davranche@univ-rennes1.fr 


\section{Highlights:}

- At high and low metal loading, the structure of Sm and $\mathrm{Yb}$ complexes with humic acid are determined by EXAFS spectroscopy.

- Model VII predicts that $\mathrm{Yb}$ and $\mathrm{Sm}$ tend to bind to strong humic $\mathrm{N}$-containing groups at low metal loading.

- At low metal loading the presence of $\mathrm{N}$ could not be demonstrated, in contrast with reference complexes with IDA, NTA or EDTA.

- At high metal loading, carboxylic humic groups are found to be coordinated in bidentate mode.

- The results are discussed in the context of cation competition and supramolecular structure of metal-humate complexes.

KEYWORDS: rare earth elements, humic acid, EXAFS, metal loading, modeling. 
ABSTRACT. Humic substances are major natural complexing agents that strongly influence the cycling of metal cations in the environment. The metal to humic acid (HA) concentration ratio (metal loading) can significantly impact the overall HA complexation properties in natural soils and waters. At low metal loading, cations bind to strong multi-carboxylate or phenolate sites of HA. In addition, these strong sites might contain soft Lewis bases such as N or S, the contribution of which is still a matter of debate. Based on the possible ability of Rare Earth Elements (REE) to trace HA binding properties, the present study aimed at evaluating the influence of REE-loading on the HA binding mechanisms of two hard Lewis acids, $\mathrm{Sm}^{3+}$ and $\mathrm{Yb}^{3+}$. Extended X-ray Absorption Fine Structure (EXAFS) at the $\mathrm{Sm}$ and $\mathrm{Yb} \mathrm{L}_{\mathrm{III}}$ edge was used to analyze the local coordination of these intermediate and heavy REE ions, respectively, in a low and a high REE-loading HA sample. Data were interpreted by comparison with EXAFS data for a series of aqueous REE complexes with iminodiacetic acid (IDA), nitrilotriacetic acid (NTA), ethylenediaminetetraacetic acid (EDTA) and a carboxylicgrafted resin. In all these samples, both a Yb-O ( 2.31 $\AA$ ) and a Yb-N $(\sim 2.50 \AA)$ backscattering path could be identified in the first coordination shell of $\mathrm{Yb}$. At low REE loading, the first coordination shell around the $\mathrm{Yb}$ bond to $\mathrm{HA}$ is described by a single $\mathrm{Yb}-\mathrm{O}$ backscattering path, i.e. the presence of $\mathrm{N}$ could not be evidenced. By contrast, the carboxylic-grafted resin exhibits both a short $(2.31 \AA)$ and a long Yb-O average distance $(2.44$ $\AA$ ), suggesting the coordination of carboxylate is bidentate. The Fourier transform of the high loading HA samples exhibits a broad first shell peak possibly described by two Yb-O distances (2.29 and $2.43 \AA$ ) suggesting two coordination modes of the carboxylic groups. Different Yb-HA complex structures can therefore be observed at different metal loadings. Unfortunately, the Sm EXAFS spectra could only be recorded up to $\mathrm{k}=10 \AA^{-1}$. There was no evidence of either a clear difference between the metal loadings or with Yb-HA complex structures. A comparison between the EXAFS results, PHREEQC-Model VI simulations, and 
the pattern of the REE complexation constants with simple organic ligands (REE:ligand 1:1 and 1:2 complexes) provides evidence that, at high loading, REE are bound to HA through biligand complexes without any chelation effect in which REE may potentially act as a cation bridge between two organic molecules. At low loading, the fact that $\mathrm{N}$ could not be detected in the $\mathrm{Yb}$ first shell suggests that, at low loading, $\mathrm{Yb}$ binds to O-containing groups of $\mathrm{HA}$ rather than $\mathrm{N}$-containing groups. This may call into question the definition of HA strong sites for REE binding such as soft Lewis base-containing sites. 


\section{INTRODUCTION}

Humic substances, such as humic acids (HA), are ubiquitous in the environment and show high binding capacity for dissolved cations. Although huge efforts have been made to determine HA-cation thermodynamic complexation constants in environmentally relevant conditions (e.g. Benedetti et al., 1995; Tipping, 1998; Kinniburgh et al., 1999; Iglesias et al., 2003; Milne et al., 2003; Marang et al., 2008; Catrouillet et al., 2014), the mechanisms underlying these complexation reactions are not yet fully understood. This is mainly due to the extreme heterogeneity of functional groups in HA (Sutton and Sposito, 2005). Metals can form a large variety of complexes with HA, leading to apparent complexation constants that depend on the $\mathrm{pH}$ and on the metal/HA concentration ratio (metal loading). The major HA cation-binding groups are the carboxylic and phenolic groups (Ritchie and Perdue, 2003), but less abundant softer Lewis bases (e.g. N- and S-containing groups) can also enhance cationHA complexation (Tipping 1998, Hesterberg et al., 2001). When several functional groups bind to a single cation, the denticity of the complex increases, e.g., a bidentate complex forms when two functional groups bind to the same cation. Such multidentate complexes can either form a cation bridge between different organic molecules (Kunhi Mouvenchery et al., 2012) or a chelate complex when the binding groups are sufficiently close enough to each other. The cation-HA complexation constant can then be enhanced due to the chelation effect (Martell and Hancock, 1996). However, steric effects limit the abundance of chelating ligands in HA.

Rare earth elements (REE) are a group of fourteen stable metallic elements of unique importance in geosciences because of their coherent chemical properties (Henderson, 1984). Characteristic REE signatures in waters can thus be related to specific biogeochemical processes (such as weathering, sorption or complexation). In organic-rich waters, field and experimental studies have provided evidence for dominant REE binding to colloidal humic substances (Tang and Johannesson, 2003; Pourret et al., 2007). In the laboratory, results from 
REE-HA complexation experiments have shown two distinct REE patterns that depend on the relative HA to REE concentration ratio, which may be interesting tracers of HA binding properties. These two patterns correspond to (i) preferential binding of Middle Rare Earth Elements (MREE) at a high REE loading (Pourret et al., 2007) and (ii) preferential binding of heavy REE (HREE) at a low REE loading (Sonke and Salters, 2006) (Figure S1). The first pattern is interpreted as a preferential complexation of MREE to the low affinity but abundant carboxylic groups. In contrast, the second pattern might be explained by the "lanthanide contraction effect", which may favor complexation of heavy REE to high-affinity but less abundant multi-ligand sites (chelates). Such increasing denticity of the complexes with decreasing REE loading was supported by modelling calculations that used a semimechanistic binding model (Model VI: Tipping, 1998; PHREEQC-Model VI: Marsac et al., 2010; 2011). However, this hypothesis is not yet supported by structural data (Rabung and Geckeis, 2008).

In advanced models, several cation-HA binding processes are explicitly or implicitly taken into account. In particular, Model VI (or Model VII: Tipping et al., 2011) account for both the chelation effects and the participation of $\mathrm{N}$ - and S-containing groups via one single parameter, $\Delta \mathrm{LK}_{2}$, that is specific for each cation. This parameter is applied to a small amount of binding groups to which all cations are expected to bind at low metal loading. Although $\Delta \mathrm{LK}_{2}$ is generally estimated from cation- $\mathrm{NH}_{3}$ complexation constants, spectroscopic studies have shown that some cations bind to other types of high affinity functional groups. For instance, $\mathrm{Hg}(\mathrm{II})$ preferentially binds to thiol groups at a low metal/DOC ratio (e.g. Hesterberg et al., 2001), whereas $\mathrm{Cu}$ (II) forms a chelate ring, the size of which depends on the weak or strong sites involved (Manceau and Matynia, 2010). The contribution of amino groups to $\mathrm{Cu}-$ HA binding is mainly supported by thermodynamic considerations (e.g. Carbonaro et al., 2011). According to the hard and soft acid and base principle given by Pearson (1963), the 
soft $\left(\mathrm{Hg}^{2+}\right)$ and intermediate $\left(\mathrm{Cu}^{2+}\right)$ acids are expected to bind strongly to soft bases such as $\mathrm{N}$ - and S-containing HA groups. By contrast, REE trivalent ions are hard acids with very low affinity for $\mathrm{NH}_{3}$, which suggest that other types of HA functional groups may explain the metal loading effect on REE-HA complexation (Marsac et al., 2011). However, REE binding to $\mathrm{N}$-containing ligands in HA also cannot be excluded in view of the high stability of the REE complexes with smaller N-containing ligands (e.g. in Byrne and Li, 1995; Choppin et al., 2006).

Recently, several studies have demonstrated the ability of Extended X-ray Absorption Fine Structure (EXAFS) to investigate the nature of REE-organic matrix complexes (Wang et al., 2001; Ding et al., 2006; Ngwenya et al., 2009; Takahashi et al., 2010), as well as of REEmineral surface complexes (Ohta et al., 2009a,b). EXAFS cannot directly differentiate between nearest neighbors of the REE ion having comparable atomic numbers, such as $\mathrm{O}$ and $\mathrm{N}$, because these neighbors have similar photoelectron backscattering amplitude functions. However, since interatomic distances can be accurately determined by EXAFS, O and $\mathrm{N}$ can often be differentiated as nearest neighbors of the REE, based on distinct coordination bond lengths. For instance, crystallographic data on REE-organic compounds (e.g. Nakamura et al., 1995; Janicki et al., 2008) as well as EXAFS analysis of comparable aqueous complexes (Narita et al., 2001; Mathur et al. 2006; Denecke et al., 2007) show that REE-N bonds are generally longer than REE-O ( 0.2-0.3 $\AA$ difference). In addition, EXAFS studies have revealed different binding sites or coordination modes between LREE and HREE at the surface of bacterial cells (Takahashi et al., 2010) as well as on mineral surfaces (Ohta et al., 2009a,b). Similar differences between LREE and HREE binding modes are expected for complexation to HA, as suggested by thermodynamic calculations (Marsac et al., 2011), cation competition experiments (Marsac et al., 2012, 2013) and infra-red spectroscopy measurements (Gangloff et al., 2014). 
The main objective of the present study is to investigate the molecular environment of REE bound to humic acid at various loadings in order to determine which sites are involved in REE complexation to humic acids. The results are closely compared with the PHREEQC/Model VI prediction of REE speciation in the HA molecule to understand the meaning of the "strong binding site term" $\Delta \mathrm{LK}_{2}$ for REE, i.e. whether it is due to a chelation effect or to the participation of N-containing ligands in the complex. In addition the structure of MREE (Sm) and HREE ( $\mathrm{Yb}$ ) complexes with HA are determined and compared in order to verify whether all REE share the same type of preferential binding sites, as previously questioned.

\section{MATERIALS AND METHODS}

All chemicals were of analytical grade, with all experimental solutions prepared with doubly deionised water (Milli-Q system, Millipore $\left.{ }^{\circledR}\right)$. Synthetic REE solutions were prepared from a nitrate REE standard solution (1000 mg.L $\mathrm{L}^{-1}$, Accu Trace Reference Standard). All experiments were performed at room temperature, i.e. $20^{\circ} \mathrm{C} \pm 2$.

\subsection{Sample preparation}

Both $\mathrm{Sm}^{3+}$ (middle REE) and $\mathrm{Yb}^{3+}$ (heavy REE) were chosen for their redox stability, which minimizes radiation damage under the synchrotron beam. Leonardite Humic acid (HA) was obtained from the International Humic Substances Society (IHSS). For each sample, 500 mg of HA was dissolved in $100 \mathrm{~mL}$ of a $0.01 \mathrm{M}$ of $\mathrm{NaOH}+0.1 \mathrm{M} \mathrm{NaNO}_{3}$ solution overnight. This HA solution was then increased to $500 \mathrm{~mL}$ with a $0.1 \mathrm{M} \mathrm{NaNO}_{3}$ solution and adjusted to $\mathrm{pH} 7$ by adding $1 \mathrm{MHNO}_{3}$. REE were added to this $\mathrm{HA}$ solution and the $\mathrm{pH}$ was readjusted to 7 by adding small amounts of $\mathrm{NaOH}$. Two REE concentrations were investigated to study the 
metal loading effect: $10^{-3}$ and $10^{-5} \mathrm{M}$, corresponding approximately to $20 \%$ and $0.2 \%$ of the total Leonardite HA proton exchange capacity (PEC). These experimental conditions are similar to those in previous studies (i.e. Sonke and Salters, 2006; Pourret et al. 2007; see supporting information for more details), and they ensure that nearly $100 \%$ of the REE are complexed to HA. After 1 week, the HA suspensions were concentrated by tangential ultrafiltration at $5 \mathrm{kDa}$ (Labscale TFF system equipped with a Pellicon XL membrane, Millipore $^{\mathrm{TM}}$ ) in order to reduce the volume of the HA solutions from $500 \mathrm{~mL}$ to $50 \mathrm{~mL}$, and dried at room temperature. The solid contained 150 and $1.5 \mathrm{mg} \cdot \mathrm{g}^{-1} \mathrm{HA}$ of each REE, for the high and low loading respectively. These REE-HA samples at low and high REE loading are referred to as L7 and $\mathrm{H} 7$ samples in the following text.

Aqueous $\mathrm{Sm}^{3+}$ - and $\mathrm{Yb}^{3+}$-organic complexes were prepared to mimic complexes formed with HA. Iminodiacetic acid (IDA), nitrilotriacetic acid (NTA) and ethylenediaminetetraacetic acid (EDTA) were used as reference chelate ligands with different numbers of carboxylic and amino-groups (Figure S2). NTA and EDTA were purchased from Sigma-Aldrich ${ }^{\mathrm{TM}}$. They were reacted with dissolved $\mathrm{Sm}^{3+}$ or $\mathrm{Yb}^{3+}$ in $1: 1$ ratio at a concentration of $5 \times 10^{-3} \mathrm{M}$ at $\mathrm{pH} 7$ and with $0.1 \mathrm{M}$ of $\mathrm{NaNO}_{3}$ in order to obtain dissolved REE-NTA or -EDTA complexes. The $\mathrm{Sm}^{3+}-$ and $\mathrm{Yb}^{3+}$-IDA complexes were prepared using a cation exchange resin (Amberlite chelating resin IRC-748) purchased from Supelco ${ }^{\mathrm{TM}}$. This resin consists of a polyacrylic copolymer grafted with IDA and has a total exchange capacity of $4.4 \mathrm{meq} \mathrm{g}^{-1}$. A $1 \mathrm{~g}$ resin suspension was prepared at $\mathrm{pH}=7,0.1 \mathrm{M} \mathrm{NaNO}_{3}$ and $5 \times 10^{-5} \mathrm{M}$ of Sm or $\mathrm{Yb}$ (total sample volume: $10 \mathrm{~mL}$ ) one week before the synchrotron beamtimes. For the EXAFS data measurements, the solution was discarded and the wet resin was placed in a sample holder. Additionally, a carboxylic-grafted resin (Amberlite weak cation exchanger resin IRC-86; total exchange capacity: 10.7 meq. $\mathrm{g}^{-1}$; referred to as $\mathrm{COOH}$ resin in the following text) was chosen as a reference for REE binding to a single carboxylate ligand. The 
procedure for the carboxylic resin was the same as for the IDA resin. Both resins were consequently loaded at approximately $1 \%$ of their exchange capacity by REE.

Under some of our experimental conditions, when considering the total $\mathrm{Sm}$ and $\mathrm{Yb}$ concentration, the saturation index with respect to amorphous hydroxides might be exceeded in the absence of organic ligands. Indeed, the solubility limit of trivalent lanthanide/actinides for $\mathrm{pH}=7$ and an ionic strength of $0.1 \mathrm{M}$ is approximately $10^{-3} \mathrm{M}$ (Neck et al., 2009). However, prior to the preparation of the samples, speciation calculations were made using the IUPAQ stability constant database (2001) and the experimental conditions were defined in order to avoid precipitation in the presence of the investigated ligands. EDTA, NTA and IDA are strong chelating ligands and complex almost $100 \%$ of REE in equimolar conditions at $\mathrm{pH}$ $=7$. For the carboxylic resin, only a $1: 1 \mathrm{Sm}^{3+}$ - and $\mathrm{Yb}^{3+}$-acetate complexation was considered in the calculation. The wide excess of carboxylic groups is expected to avoid any precipitation.

\subsection{EXAFS measurements and analyses}

$\mathrm{Yb}(8.9 \mathrm{keV})$ and $\mathrm{Sm}(6.7 \mathrm{keV}) \mathrm{L}_{\mathrm{III}}$-edge EXAFS data were collected at room temperature using a Si(111) monochromator and 19-element and 13-element Ge solid-state Canberra fluorescence detectors on beamlines BL12C at the KEK Photon Factory (Tsukuba, Japan) and BM23 at the European Synchrotron Facilities (ESRF, Grenoble, France), respectively. The $\mathrm{Yb}$ and Sm-HA powders were analyzed in pellet form at beamline BL12C. EDTA and NTA complexes were recorded in aqueous solution on BL12C while IDA and $\mathrm{COOH}$ wet resins were recorded on BM23. Between 3 and 30 scans of 40 min were collected for each sample depending on the signal-to-noise ratio. No radiation damage was observed during data acquisition, since multiple scans gave identical spectra to one another. 
EXAFS data were extracted using the Athena program with the energy threshold taken at the first inflection point of the edge (Ravel and Newville, 2005). The $k^{3}$-weighted EXAFS data were Fourier transformed over the 2.5 - 9 and $2.5-12.5 \AA^{-1} k$-ranges for $\mathrm{Sm}$ and $\mathrm{Yb}$, respectively, after applying a Kaiser-Bessel window with a Bessel weight value of 2.5. The $k^{3}$-weighted EXAFS data were fit using a classical shell-by-shell procedure using the Artemis program (Ravel and Newville, 2005) based on the IFEFFIT code (Newille 2001). Theoretical backscattering amplitude and phase-shift functions used in this fitting procedure were calculated using the FEFF8.2 code (Ankudinov et al., 1998) using the crystal structures of $\left[\mathrm{C}\left(\mathrm{NH}_{2}\right)_{3}\right]_{2}\left[\mathrm{Yb}(\mathrm{EDTA})\left(\mathrm{H}_{2} \mathrm{O}\right)_{2}\right] \mathrm{ClO}_{4} \cdot 6 \mathrm{H}_{2} \mathrm{O}$ (referred to as Yb-EDTA; Janicki et al., 2008) and $\mathrm{Yb}(\mathrm{HCOO})_{3}\left(\mathrm{H}_{2} \mathrm{O}\right)_{2}$ (referred to as $\mathrm{Yb}$-formate; Furmanova et al., 1983) and the structure of $\mathrm{Na}\left[\mathrm{Eu}(\mathrm{EDTA})\left(\mathrm{H}_{2} \mathrm{O}\right)_{3}\right] \cdot 5 \mathrm{H}_{2} \mathrm{O}$ (referred to as Eu-EDTA; Nakamura et al., 1995) replacing $\mathrm{Eu}$ by $\mathrm{Sm}$, which are neighbors in the periodic table. Similar results were obtained when replacing Nd by Sm in the structure of Nd-EDTA (Nakamura et al., 1995). The fit quality was assessed using the reduced $\chi^{2}$, i.e. the $\chi^{2}$ weighted by the degree of freedom. Reported uncertainties in the present study are obtained by the fitting procedure. Nevertheless, the uncertainties should be considered, in the best case, as $\pm 20 \%$ on coordination numbers, \pm $0.02 \AA$ on bond distances and $\pm 20 \%$ on Debye-Waller factors (O’Day et al., 1994).

\subsection{REE-HA complexation using Model VI}

The humic ion-binding Model VI was developed by Tipping (1998) and a detailed description can be found in his article. In Model VI, HAs are described as discrete acido-basic chemical functional groups (carboxylic and phenolic) able to bind cations, forming either monodentate, bidentate or tridentate complexes. When referring to this modeling approach in the present study, these binding complexes will be denoted as "multi-ligand" sites to distinguish them from actual coordination complexes with given denticity. The proportion of 
mono-, bi- and tri-ligands sites in the model is set to $43.5 \%, 50 \%$ and $6.5 \%$ of the total site density. For most of the bi- and tri-ligand sites, no chelation effect is considered. For instance, the formation constant $\left(\log \mathrm{K}_{1-2}\right)$ between a cation and a bi-ligand site involving site 1 and site 2 is defined as $\log \mathrm{K}_{1-2}=\log \mathrm{K}_{1}+\log \mathrm{K}_{2}$, where $\log \mathrm{K}_{1}$ and $\log \mathrm{K}_{2}$ represent the corresponding formation constants for the mono-ligand-cation complexes. For a minor proportion of the bi- and tri-ligand sites $(9.9 \%)$, the stability constant is increased by a "strong binding site term" $\left(\Delta \mathrm{LK}_{2}\right)$ that accounts for both the chelation effect and the potential participation of additional softer atoms (e.g. $\mathrm{N}$ or $\mathrm{S}$ ) in the binding. The effect of ionic strength is considered by applying a correction term to the stability constants based on the Gouy-Chapman theory. Finally, cation accumulation in the vicinity of an HA molecule is calculated with the Donnan model.

Model VI was originally implemented in the speciation code WHAM 6. Model VI equations were recently introduced into PHREEQC (version 2) developed by Parkhurst and Appelo (1999) for the whole REE group (Marsac et al., 2011). PHREEQC is a speciation code, which was designed to perform speciation and saturation-index calculations in water. PHREEQC/Model VI coupling allowed the REE-HA binding description to be improved, notably by removing the linear relationship imposed by Model VI between the carboxylicand phenolic-cation binding parameters, and by imposing new constraints. A detailed description is given in Marsac et al. (2011). In the present study simulations were performed using PHREEQC/Model VI for the low and high REE loading experiments to determine (1) the average number of HA functional groups coordinated to $\mathrm{Sm}$ and $\mathrm{Yb}$ and (2) the fraction of REE complexed to the strong binding site (i.e., $\Delta \mathrm{LK}_{2}$ dependent), which was compared to the structural parameters determined by EXAFS.

\section{RESULTS}




\subsection{REE speciation in the HA samples studied as predicted with PHREEQC/Model VI.}

As discussed in detail in the supporting information, the presently investigated experimental conditions are similar to the ones used by Sonke and Salters (2006) (i.e. low loading: Sm- and Yb-L7) and Pourret et al. (2007) (i.e. high loading: Sm- and Yb-H7) for investigating REE-HA complexation processes. Both experimental datasets were previously used to calibrate the PHREEQC/Model VI parameters for REE by Marsac et al. (2011). Smand $\mathrm{Yb}$ speciation with $\mathrm{HA}$ are calculated for the present samples using PHREEQC/Model VI. According to the predicted average number of coordinated HA ligands and the proportion of strong binding sites, $\mathrm{Sm}$ and $\mathrm{Yb}$ show the same speciation. The predicted average number of HA groups coordinated to both REE is 2.1 (H7) and 2.8 (L7): 13\% of both REE are predicted to be complexed to tri-ligand sites for sample $\mathrm{H} 7$ versus $75 \%$ for $\mathrm{L} 7$. REE complexation to the strong binding sites is predicted to increase from $16 \%$ for $\mathrm{H} 7$ to $99 \%$ for $\mathrm{L} 7$. Therefore, according to PHREEQC/Model VI, significant variations in the nature of the REE-HA complexes can be expected between high (H7 samples) and low (L7 samples) REE loading. At low loading, REE speciation with HA molecules is predicted to be dominated by the strongest tri-ligand sites whereas weaker sites and bi-ligand sites are the major REE binding sites at high loading.

According to PHREEQC/Model VI, the amount of REE outer-sphere complexes in the Donnan volume was found to be insignificant and the amount of REE-mono-ligand complexes was found negligible. According to previous studies, the major difference between $\mathrm{Sm}$ and $\mathrm{Yb}$ predicted speciation with $\mathrm{HA}$ relies on the nature of the binding groups, $\mathrm{Yb}$ being more strongly bound to HA phenolic groups than Sm (Marsac et al., 2011; Gangloff et al., 2014). However, the amount of $\mathrm{Yb}$ complexed to phenolic HA groups is predicted to be only 5\% higher than Sm in the present EXAFS samples. Indeed, by studying a single REE and a 
purified HA, no inter-cation (including inter-REE) competition occurs and each type of HA site is available for $\mathrm{Sm}$ or $\mathrm{Yb}$ complexation. This leads to more similar predicted speciation for Sm and Yb with Model VI than in Marsac et al. (2011). Furthermore, REE-O bond distances in carboxylate and phenolate complexes might be too similar to be differentiated by EXAFS in the present study (e.g. as for U(VI): Schmeide et al., 2003; or for Np(V): Sachs et al., 2005).

\subsection{EXAFS analysis of the reference Yb-ligand complexes.}

Figure 1 displays the $k^{3}$-weighted EXAFS spectra and their corresponding Fourier transforms for all $\mathrm{Yb}-\mathrm{HA}$ and reference organic complexes for $\mathrm{Yb}$. All reference spectra exhibit a first-shell peak at around $\mathrm{R}+\Delta \mathrm{R} \sim 1.9 \AA$ in the FT which can be assigned to $\mathrm{O}$ or $\mathrm{N}$. A second contribution is observed at $\mathrm{R}+\Delta \mathrm{R} \sim 2.6 \AA$. The intensity of this second peak increases with the number of coordinating groups in the complex (i.e. EDTA > NTA > IDA), which suggests that it can be assigned to $\mathrm{C}$ in the second shell. It is not observed clearly for the carboxylic resin ( $\mathrm{Yb}-\mathrm{COOH}$ sample), in which the REE ion is expected to bind to a single carboxylic group. Finally, a third contribution is observed for $3.5<\mathrm{R}+\Delta \mathrm{R}<4.5 \AA$. This signal is broad and seems to contain at least two contributions at $\mathrm{R}+\Delta \mathrm{R} \sim 3.7 \AA$ and $\mathrm{R}+\Delta \mathrm{R}$ $\sim 4.1 \AA$, as can be observed for the double peak on the FT of Yb-EDTA. If Yb-(hydr)oxide or polynuclear species were formed, an interaction between $\mathrm{Yb}-\mathrm{Yb}$ would be observed at this distance (e.g. $\mathrm{Yb}_{2} \mathrm{O}_{3}$, Kizler et al. 1997). However, $\mathrm{Yb}$-(hydr)oxide precipitation is not supported by preliminary thermodynamic calculations. Furthermore, the intensity of this peak also increases with the number of coordinating groups in the ligand (e.g. EDTA > NTA > IDA), suggesting more distant atoms or multiple scattering.

Results of EXAFS spectra fitting for the Yb complexes are reported in Table 1. For the Yb-EDTA sample, the best fit of the first coordination sphere around $\mathrm{Yb}$ is obtained with 
$6.5 \pm 0.8 \mathrm{O}$ atoms at $\mathrm{R}=2.29 \pm 0.01 \AA$ and $2.3 \pm 0.4 \mathrm{~N}$ atoms at $2.50 \pm 0.03 \AA$. This result is in relatively good agreement with crystallographic data. According to Janicki et al. (2008), in both crystalline and dissolved states, EDTA forms a 1:1 chelate complex in which $\mathrm{Yb}$ is bound to four carboxylic groups in a monodentate fashion, two amino groups and two water molecules. A cartoon of the structure of the Yb-EDTA complex is shown in figure S3. However, the two types of $\mathrm{Yb}-\mathrm{O}$ distances cannot be resolved with our EXAFS data. In the crystalline form, the first coordinating oxygen atoms around $\mathrm{Yb}$ in the $\mathrm{Yb}$-EDTA complex can thus be considered as a shell of six $\mathrm{O}$ atoms at a distance of $2.28 \AA$ on average (standard deviation: $0.04 \AA$ ), which compares well with the distance of $2.29 \pm 0.01 \AA$ determined by EXAFS (Table 1). The Yb-N distance observed by EXAFS $(2.50 \pm 0.03 \AA)$ is slightly shorter than that in the crystalline form (2.58 $\AA$; standard deviation: $0.01 \AA$ ), which could be attributed to a solvation effect. Nevertheless, the average Yb-first neighbor distance determined by EXAFS in the dissolved Yb-EDTA is similar to that reported for crystalline Yb-EDTA ( 2.34 $)$ ). It is important to note that XRD provides more accurate bond distances than EXAFS. The standard deviation calculated here from the crystallographic data does not correspond to the uncertainty associated with a bond distance determination, as is the case for EXAFS analysis. It would rather indicate static disorder, which corresponds to the DebyeWaller factor determined by EXAFS.

In the second shell of $\mathrm{Yb}, 8.3 \pm 2.0 \mathrm{C}$ atoms are found at $3.23 \pm 0.01 \AA$, in agreement with the $10 \mathrm{C}$ atoms expected to surround $\mathrm{Yb}$ at an average distance of $3.28 \AA$ (standard deviation: $0.10 \AA$ ) in the Yb-EDTA complex. This $\mathrm{C}$ atom shell actually consists of two sets of atoms with distinct average $\mathrm{Yb}-\mathrm{C}$ distances (3.18 and $3.36 \AA$; standard deviations: 0.02 and $0.06 \AA$, respectively), due to the dissimilar $\mathrm{Yb}-\mathrm{O}$ and $\mathrm{Yb}-\mathrm{N}$ bond distances. This cannot be resolved by our EXAFS data. However, it explains the high Debye-Waller factor value (i.e. $0.012 \AA^{2}$ ) for the $\mathrm{Yb}-\mathrm{C}$ shell (Table 1). Finally, the third contribution to the EXAFS spectrum 
could only be fit with a multiple scattering path $\mathrm{Yb}-\mathrm{O}-\mathrm{O}$ (or $\mathrm{Yb}-\mathrm{C}-\mathrm{O}$ ) within the carboxylate complex $(\mathrm{CN}=10.3 \pm 2.6 ; \mathrm{R}=4.44 \pm 0.01 \AA)$, where the distant $\mathrm{O}$ atom is an uncoordinated oxygen of the carboxylate. Attempts to include other paths did not result in reliable EXAFS parameters. The Yb-O-O path length is in good agreement with crystallographic data (4.39 А; standard deviations: 0.03). The atoms are relatively well aligned within this $\mathrm{Yb}-\mathrm{O}-\mathrm{O}$ (or $\mathrm{Yb}$ C-O) path, with bond angles close to $150^{\circ}$, which favors the observation of multiple scattering by EXAFS.

NTA and IDA are relatively similar molecules to EDTA. Only the number of coordinated functional groups differs. In the NTA molecule, three carboxylate and one nitrogen are coordinated to $\mathrm{Yb}$. In the IDA molecule two carboxylate and one nitrogen are coordinated to $\mathrm{Yb}$. Therefore, the structure of $\mathrm{Yb}-\mathrm{NTA}$ and -IDA are discussed in comparison to $\mathrm{Yb}$-EDTA. Yb-NTA and Yb-IDA both show approximately $7 \mathrm{O}$ in the first shell at $2.31 \pm$ $0.01 \AA$ as well as $2.5 \pm 0.5 \mathrm{~N}$ at 2.48 (NTA) and $2.51 \pm 0.03 \AA$ (IDA). As for EDTA, the Debye-Waller factor for the $\mathrm{Yb}-\mathrm{N}$ path had to be constrained to be equal to that of the $\mathrm{Yb}-\mathrm{O}$ path. This might explain the apparently inconsistent number of $\mathrm{N}(2.5 \pm 0.5$ compared to the theoretical value of 1), in addition to the large uncertainty on the coordination numbers by EXAFS. Nevertheless, the determined $\mathrm{Yb}-\mathrm{N}$ bond distances for the three complexes are in good agreement, as well as with the bond distances determined by Narita et al. (2001) in the Yb-(IDA) $)_{3}$ aqueous complex (Yb-O: $2.30 \AA$; $\mathrm{Yb}-\mathrm{N}: 2.46 \AA$ ). The $\mathrm{Yb}-\mathrm{C}$ bond distances in NTA and IDA are determined to equal $3.23 \pm 0.02$ and $3.30 \pm 0.03 \AA$, respectively. As for EDTA, the Debye-Waller factor for the $\mathrm{C}$ shell is relatively high $\left(0.016\right.$ and $0.020 \AA^{2}$ for NTA and IDA, respectively), which appears to be characteristic of the dissimilar $\mathrm{Yb}-\mathrm{O}$ and Yb-N bond distances. The most distant shell observable on the FT is attributed to multiple scattering and the $\mathrm{Yb}-\mathrm{O} / \mathrm{C}-\mathrm{O}$ bond distances are determined to equal $4.44 \pm 0.01 \AA$ (NTA) and $4.48 \pm 0.02 \AA$ (IDA). Although subjected to large uncertainties, the $\mathrm{C}$ and $\mathrm{MS}$ 
coordination number decreases consistently with the number of coordinating groups in the ligand: $\operatorname{EDTA}(\mathrm{C}: 8.3$; MS: 10.3) > NTA(C: 6.5; MS: 5.9) > IDA(C: 2.5; MS: 3.3).

In contrast to the previous complexes, the Yb-carboxylic resin sample exhibits a slightly longer $\mathrm{Yb}-\mathrm{O}$ distance, which is determined to equal $2.35 \pm 0.01 \AA$ when the spectrum is fitted with a single shell. This $\mathrm{Yb}-\mathrm{O}$ bond distance is longer than in the aqueous ion (Ohta et al., 2008). Furthermore, the first shell peak on the FT spectrum shows a small shoulder at R $+\Delta \mathrm{R} \sim 2.3 \AA$. It suggests that a carboxylate group coordinates to $\mathrm{Yb}$ in bidentate $\left(\mathrm{COO}_{\mathrm{bi}}\right)$ rather than in monodentate mode $\left(\mathrm{COO}_{\text {mono }}\right)$. An illustration of both coordination modes is given in figure $\mathrm{S} 3$, for the case of the $\mathrm{Yb}$-actetate complex. Indeed, lanthanides or actinides-O bond distances in the case of $\mathrm{COO}_{\mathrm{bi}}$ are generally longer than for $\mathrm{COO}_{\text {mono }}$ as shown for $\mathrm{Eu}$ polyacrylic acid (Montavon et al., 2006) or as discussed for U(VI) (Schmeide et al., 2003; and references therein). This is particularly well illustrated in the structure of Yb-formate determined by XRD (Furmanova et al., 1983), where formate coordinated to $\mathrm{Yb}$ in both modes. The difference in the two Yb-O bond distances is $0.13 \AA$ ( 2.27 versus $2.40 \AA$ ). Also, $\mathrm{Yb}-\mathrm{C}$ is $0.46 \AA$ shorter in $\mathrm{COO}_{\mathrm{bi}}-\mathrm{Yb}(2.77 \AA)$ than $\mathrm{COO}_{\text {mono }}-\mathrm{Yb}(3.23 \AA)$ for geometrical reasons (i.e. a much smaller $\mathrm{Yb}-\mathrm{O}-\mathrm{C}$ angle). This structure is tested by considering two distinct $\mathrm{Yb}-\mathrm{O}$ shells, as well as an $\mathrm{Yb}-\mathrm{C}$ shell. Debye-Waller factors are set equal for all paths. This fit leads to a twice lower reduced- $\chi^{2}$ than in the first case. $4.3 \pm 1.6 \mathrm{O}$ are found at $2.31 \pm 0.02 \AA$, in better agreement with the Yb-aqueous ion (Ohta et al., 2008) and $2.9 \pm 0.8$ $\mathrm{O}$ at $2.44 \pm 0.03 \AA$. Also, the $\mathrm{Yb}-\mathrm{C}$ bond distance is equal to $2.75 \pm 0.03 \AA$. Consistently, the coordination number of $\mathrm{C}$ is approximately half of the long $\mathrm{Yb}-\mathrm{O}$ path $(1.4 \pm 0.8)$. The latter results are in relatively good agreement with the structure of $\mathrm{Yb}$-formate and suggest that $\mathrm{Yb}$ is coordinated to one carboxylate in a bidentate mode on the resin surface.

\subsection{EXAFS analysis of the Yb-HA complexes.}


The HA samples show slight dissimilarities that can mainly be seen on the FT spectra. Analyzed over the same k-range $\left(2.5<\mathrm{k}<12.5 \AA^{-1}\right)$, the first shell peak is broader for $\mathrm{Yb}-\mathrm{H} 7$ than for Yb-L7. It can also be globally seen by the more attenuated oscillations of the $\mathrm{k}^{3}$ weighted Yb-H7 EXAFS spectrum for high $\mathrm{k}$ values $\left(\mathrm{k}>9 \AA^{-1}\right)$. No clear node in the $\mathrm{k}$-space spectrum, which would evidence two well-defined distances in the first shell, can be identified visually. Moreover, $\mathrm{Yb}-\mathrm{L} 7$ exhibits a small peak at $\mathrm{R}+\Delta \mathrm{R} \sim 2.6 \AA$, the amplitude of which is comparable to the $\mathrm{Yb}$-IDA sample, as well as some signals for $3.5<\mathrm{R}+\Delta \mathrm{R}<4.5 \AA$, whereas Yb-H7 shows no signal for the more distant shell. This is consistent with our expectation that a higher metal loading would result in a less well defined EXAFS structure with regards to the larger variability in the nature of the REE-HA complexes compared with low metal loading where a few types of strong sites are expected to bind REE.

The same approach as to the reference ligands was applied to fit the EXAFS data recorded for the $\mathrm{Yb}-\mathrm{HA}$ samples. For $\mathrm{Yb}-\mathrm{L} 7$, approximately nine $\mathrm{O}$ are found at $2.32 \pm 0.01$ $\AA$ in the first shell. According to the definition of Model VI for Yb-HA binding and the present speciation calculations, $\mathrm{Yb}$ is $99 \%$ complexed to HA strong sites (i.e. potentially Ncontaining sites). The Debye-Waller factor value, which is relatively large $\left(0.011 \AA^{2}\right)$ compared to the $\mathrm{Yb}-\mathrm{O}$ path for IDA $\left(0.008 \AA^{2}\right)$, suggests that a second backscatterer should be considered. As shown in the supplementary information, this hypothesis is tested by including an N-path in the fit of the Yb-L7 spectrum. However, the reduced- $\chi^{2}$ value is twice higher than by considering only one $\mathrm{Yb}-\mathrm{O}$ path and the statistical uncertainty on the coordination number for the second path is larger than the parameter value. Hence, the introduction of a second path to fit the $\mathrm{Yb}-\mathrm{L} 7$ spectrum is not relevant: the presence of $\mathrm{N}$ coordinated to Yb cannot be demonstrated. The more distant shells in Yb-L7 show $2.0 \pm 0.8 \mathrm{C}$ at $3.26 \pm 0.01 \AA$ and a $4.8 \pm 1.9 \mathrm{O}(\mathrm{MS})$ at $4.49 \pm 0.01 \AA$. These results are consistent with the three amino-carboxylic ligands, and are very similar to Yb-IDA. However, for a similar 
number of C, the Debye-Waller factor for Yb-L7 $\left(=0.007 \AA^{2}\right)$ is much smaller than for $\mathrm{Yb}$ IDA $\left(=0.020 \AA^{2}\right)$. Therefore, it is not possible to determine either a longer $\mathrm{Yb}-\mathrm{N}$ path or a high Debye-Waller for the C-shell (characteristic of dissimilar $\mathrm{Yb}-\mathrm{O}$ and $\mathrm{Yb}-\mathrm{N}$ distances) for Yb-L7. Thus, at low loading, our results suggest that $\mathrm{Yb}$ binds to O-containing groups of HA rather than $\mathrm{N}$-containing groups. However, this observation must be considered with caution. Even at low loading, Yb-HA complexes with various geometries might occur. The distribution of $\mathrm{Yb}-\mathrm{N}$ bond distances in $\mathrm{HA}$ might be relatively large, which would limit the detection of $\mathrm{N}$ as a backscatterer in the first shell of $\mathrm{Yb}$ because of destructive interferences.

When fitted with a single $\mathrm{Yb}-\mathrm{O}$ path, the $\mathrm{Yb}-\mathrm{H} 7$ sample does not exhibit a different average distance in the first shell $(2.31 \pm 0.01 \AA)$ than Yb-L7 $(2.32 \pm 0.01 \AA)$. The dampening of the oscillation at high $k$ values for the $\mathrm{Yb}-\mathrm{H} 7$ sample is consistent with the broader peak in the FT spectrum and it explains the large Debye-Waller factor $\left(0.013 \AA^{2}\right)$ obtained when fitting the first shell with a single $\mathrm{Yb}-\mathrm{O}$ path. When two $\mathrm{Yb}-\mathrm{O}$ paths are considered (Table 1), $6.4 \pm 1.2 \mathrm{O}$ at $2.29 \pm 0.02 \AA$ and $3.1 \pm 0.7 \mathrm{O}$ at $2.43 \pm 0.03 \AA$ are found. As shown in the supplementary information, a better fit is achieved. This is more particularly the case for $10<$ $\mathrm{k}<12 \AA^{-1}$, which corresponds to the region where destructive interferences between two YbO paths with $0.13<\Delta \mathrm{R}<0.16 \AA$ can be observed, in agreement with the fitted bond distances $(\Delta \mathrm{R} \sim 0.14)$. The dissimilar $\mathrm{Yb}-\mathrm{O}$ distances are consistent with the $\mathrm{Yb}$-formate structure, which suggests the presence of a carboxylate group coordinated to $\mathrm{Yb}$ in a bidentate mode. For $\mathrm{Yb}-\mathrm{H} 7$, there is no evidence for either a short $\mathrm{Yb}-\mathrm{C}$ distance for the carboxylic bidentate complexes, as for the carboxylic resin, or a longer distance for the carboxylic monodentate complexes, as observed for EDTA. The signal on the FT spectrum for the distant shells is extremely weak (Figure 2).

\subsection{Samarium}


Figure 2 displays the normalized $k^{3}$-weighted EXAFS spectra and their corresponding Fourier transforms of the 2.4-9.5 $\AA^{-1}$ k-range for the various Sm-HA and Sm-standard organic ligands. All spectra exhibit first-shell signals around $\mathrm{R}+\Delta \mathrm{R} \sim 2 \AA$. This contribution can be assigned to $\mathrm{O}$ or $\mathrm{N}$. Compared to $\mathrm{Yb}$, a lower signal intensity is obtained for the more distant shells for most of the Sm-complexes. However, a second contribution is observable at $\mathrm{R}+\Delta \mathrm{R}$ $\sim 2.8 \AA$ for Sm-EDTA and Sm-NTA. Considering that the signal of the second shell increases from IDA to EDTA, it can be assigned to $\mathrm{C}$. The same approach as that used for $\mathrm{Yb}$ is used to fit the EXAFS data for the various Sm-complexes. The results for all studied systems are presented in Table 2. In contrast to Yb, where EXAFS spectra could be recorded with a good quality up to $\mathrm{k}=13 \AA^{-1}$, Sm spectra could only be recorded up to $\mathrm{k}=10 \AA^{-1}$. Therefore, structural parameters for Sm complexes cannot be determined as precisely as in case of $\mathrm{Yb}$ complexes.

The EXAFS parameters for the aqueous Sm-EDTA complex are determined and discussed using the well-known structure of the Eu-EDTA crystal (Nakamura et al., 1995). The FT peak of the first shell was simulated with $10.2 \pm 0.9 \mathrm{O}$ at $\mathrm{R}=2.44 \pm 0.01 \AA$, which is consistent with the theoretical value of nine. The bond distance is in relatively good agreement with the Eu-O one in Eu-EDTA crystal or $\mathrm{Sm}-\mathrm{O}$ in the aqueous ion $(\mathrm{R}=2.44 \AA$; Ohta et al., 2008). The Debye-Waller factor equals $0.014 \AA^{2}$, which is a relatively high value. However, when an additional Sm-N path is included during the fit, although the bond distance is found to be approximately equal to $2.65 \AA$ (i.e. relatively consistent with crystallographic data), the reduced- $\chi^{2}$ value increases by a factor 5 and the uncertainties associated with the fitted parameters increase drastically. Therefore, it is not possible to demonstrate the presence of $\mathrm{N}$ in the first coordination sphere of $\mathrm{Sm}$ with the present data. Approximately $6.3 \pm 1.4 \mathrm{C}$ are determined at $\mathrm{R}=3.37 \pm 0.02 \AA$. This result is in good agreement with the $1: 1$ Eu-EDTA complex studied by Mathur et al. (2006), where 5.0 $\pm 1.7 \mathrm{C}$ were found at $3.31 \pm 0.03 \AA$. This 
bond distance is also in agreement with the average Eu-C one in Eu-EDTA crystal. No attempt is made to fit higher shells (e.g. MS) because of the very weak signal observed in the FT spectrum.

The same approach as for Sm-EDTA is used for the Sm-NTA complex and consistent results are found: $8.8 \pm 0.7 \mathrm{O}$ are determined at $2.44 \pm 0.01 \AA$ in the Sm first shell and $2.2 \pm$ $1.3 \mathrm{C}$ at $3.35 \pm 0.05 \AA$ in a second shell. This result is also in agreement with the $1: 2$ Eu-NTA complex studied by Mathur et al. (2006) where approximately $6.0 \pm 0.6 \mathrm{C}$ (i.e. around $3 \mathrm{C}$ per NTA molecule) were found at $3.35 \pm 0.02 \AA$.

None of the other complexes show a significant signal in a second shell. The Sm-O bond distance is also found to be equal to $2.44 \pm 0.01 \AA$ for Sm-IDA. The Sm-O bond distance for the carboxylic resin seems to be slightly longer $(2.46 \pm 0.01 \AA)$, which might suggest the presence of a carboxylate group coordinated in a bidentate fashion, as expected by analogy with the corresponding Yb sample. However, this cannot be clearly demonstrated in the case of Sm because the difference with the bond distances determined for other complexes is too small. Similar Sm-O bond distances are determined for the Sm-L7 $(2.43 \pm 0.01 \AA)$ and Sm-H7 (2.44 $\pm 0.01 \AA)$ samples. Therefore, no clear differences in the Sm-O distances in the first shell can be observed between HA complexes. The fitted coordination number in the Sm first shell is large for the $\mathrm{Sm}-\mathrm{H} 7$ sample $(11.5 \pm 2.3)$. However, it is associated with a large Debye-Waller factor value $\left(0.013 \AA^{-1}\right)$. As for $\mathrm{Yb}$, this is consistent with our expectation that a higher metal loading would result in a less well defined EXAFS structure with regards to the larger variability in the nature of the REE-HA complexes compared with low metal loading where a few types of strong sites are expected to bind REE.

\section{DISCUSSION}




\subsection{The nature of strong HA sites for REE: consequences for cation competition}

The present EXAFS analysis suggests similar local structure around $\mathrm{Yb}$ in the low loading Yb-HA complex (Yb-L7) and in the Yb-IDA model compound (Figure 1, Table 1), In spite of this similarity, EXAFS data fitting did not yield direct evidence for the presence of $\mathrm{N}$-containing ligands in the Yb-HA samples, because of the difficulty in distinguishing the minor contribution from a single $\mathrm{N}$ nearest neighbor to the first neighbor EXAFS signal, which is dominated by $\mathrm{O}$ neighbors. PHREEQC/Model VI calculations show that REE are dominantly bound to HA strong sites often attributed to the participation of soft bases (S- or $\mathrm{N}$-containing groups) in the complex. Consequently, $\Delta \mathrm{LK}_{2}$ is estimated from the cation- $\mathrm{NH}_{3}$ complexation constant. As they are minor components in HA, the number of this type of site and their respective reactivity are difficult to explicitly define in numerical models. As mentioned in the introduction, REE are hard acids and the weak REE- $\mathrm{NH}_{3}$ complexation constants, leading to low $\Delta \mathrm{LK}_{2}$ values, alone cannot explain the metal loading effect on REEHA complexation (Marsac et al., 2011). An increasing REE-HA complexation constant pattern from LREE to HREE (Sonke and Salters, 2006; Fig. S1) is characteristic of both iminodiacetic acid derivatives (e.g. in Byrne and $\mathrm{Li}, 1995)$ and simple chelating ligands (e.g. oxalate, Fig. 3; Schijf and Byrne, 2001). Nitrogen-containing groups are thus not necessary to describe REE-HA binding patterns at low metal loadings.

Marang et al. $(2008 ; 2009)$ investigated $\mathrm{Eu}^{3+}$ competition with the softer metal ion $\mathrm{Cu}^{2+}$ for HA complexation, applying batch and spectroscopic experiments. The authors studied $\mathrm{Eu}$ competitive effects on $\mathrm{Cu}-\mathrm{HA}$ complexation by varying $[\mathrm{Eu}]$, while $[\mathrm{Cu}]=20 \mu \mathrm{M}$ and $[\mathrm{HA}]=20 \mathrm{mg} \mathrm{L}^{-1}$ were kept constant at $\mathrm{pH}=5.5$ in $1 \mathrm{mM} \mathrm{KNO}_{3}$. The same method was used for assessing the competitive effect of $\mathrm{Cu}$ on Eu-HA complexation $([\mathrm{Eu}]=7 \mu \mathrm{M})$. For these high $\mathrm{Cu}$ or Eu loadings $\left(\sim 10^{-3}\right.$ and $3.5 \times 10^{-4} \mathrm{~mol} \mathrm{~g}^{-1}$, respectively) a direct Eu-Cu competition was observed. The data were modelled using NICA-Donnan. Although the 
definition of cation-HA complexation is very different between PHREEQC/Model VI and NICA-Donnan, both models assume that all cations compete for the same HA binding sites. While the competitive effect of $\mathrm{Eu}$ on $\mathrm{Cu}-\mathrm{HA}$ binding was well predicted, a systematic underestimation of Eu-HA complexation was observed. Because limited Eu-HA datasets were available at high $\mathrm{pH}$, the authors suspected that the parameters for the Eu-phenolic sites binding were not accurate. In addition to the conclusion of Marang et al. (2008; 2009), based on the differences in the hardness of both cations, the presence of some selective sites for $\mathrm{Eu}$ and $\mathrm{Cu}$, for which no competition occurs, might explain the discrepancies observed between experimentation and modeling. This hypothesis requires further experimental and modeling investigations of cation competition for HA complexation, especially at lower metal loading where the strong HA sites have more influence.

\subsection{REE-HA complexation at high loading}

The present study provides evidence for different structures for the Yb-HA complexes. The analysis of the high metal loading sample (Yb-H7) shows that carboxylates can coordinate to $\mathrm{Yb}$ in a bidentate fashion. The $\mathrm{COO}_{\text {mono }}-\mathrm{Yb}$ structure can be accommodated by both mono- and multi-carboxylic ligands (e.g. formate and EDTA) whereas $\mathrm{COO}_{\mathrm{bi}^{-}} \mathrm{Yb}$ is more easily accommodated as mono-carboxylic ligands for steric reasons. However, even at high loading, REE-HA complexation is already rather strong and the sole 1:1 REEcarboxylate (e.g. REE-acetate) stability constant cannot explain REE-HA complexation. Accordingly, in PHREEQC/Model VI, the dominant HA sites at high loading involve two ligands but without a chelation effect. The question therefore arises whether the two functional groups are located on the same HA molecule (a complex formation leading to a change in the HA molecule conformation) or if $\mathrm{Yb}$ acts as a bridge between two distinct organic molecules. Both mechanisms imply a significant change in HA molecular structure, 
as supported by a previous time resolved laser fluorescence spectroscopy (TRLFS) study of the Cm-HA complexes (Rabung and Geckeis, 2008), where variations in the fluorescence lifetimes were interpreted as a consequence of an increasing HA agglomeration at increasing metal loading (from 0.2 to $4 \%$ of the PEC, comparable to the present range of 0.2 to $20 \%$ ). However, it is not possible to state whether the aggregation is due to a partial neutralization of the organic molecule or to the formation of cation bridges. This might be further discussed by comparing the REE stability constant patterns for $1: 1$ and $1: 2$ complexes with small carboxylic ligands (e.g. acetate), 1:1 complexes with dicarboxylic, chelate ligands (e.g. oxalate and malonate) and the REE-HA pattern at high loading. Figure 3 presents the corresponding La-normalized complexation patterns. It includes the average 1:1 and 1:2 REEmonocarboxylic ligand patterns discussed by Smith et al. (1985). Both 1:1 and 1:2 patterns increase from LREE to MREE, and then decrease to HREE. The same conclusion can be drawn with more recent REE-acetate data (Zotov et al., 2002). Therefore, although REE speciation in HA is dominated by the bi-ligand sites in Model VI, the pattern is similar to the 1:2 complex formation with small carboxylates. By contrast, REE-oxalate complexation is stronger than REE-acetate but the 1:1 pattern (Fig. 3; Schijf and Byrne, 2001) increases globally from LREE to HREE, like for malonate (not shown). Therefore, this comparison suggests that at high loading, REE might act at least partly as cationic bridges between different organic molecules. This mechanism is not taken into account in presently available humic-ion binding models and might deserve further experimental investigation.

\section{CONCLUSION}

In the present study, the local structure of Sm-HA and Yb-HA complexes was investigated by EXAFS at $\mathrm{pH}=7$ at high and low metal loading. Previous complexation and modeling studies showed that REE speciation was dominated by weak and strong HA sites at 
high and low loading, respectively. According to PHREEQC/Model VI, preliminary calculations showed that at high loading the weaker sites are represented by bi-ligand sites, consistently with the stronger REE-HA binding compared to mono-carboxylic ligands (e.g. acetate). At lower loading, the stronger sites are tri-ligands potentially exhibiting Ncontaining groups as an additional ligand. The EXAFS analysis of the Yb-HA samples shows different structures of the complexes. At high loading, HA carboxylic groups are shown to bind to $\mathrm{Yb}$ in a bidentate fashion. This configuration might not be easily adopted in a 1:1 complex with a di-carboxylic ligand. The REE-HA complexation pattern at high loading shows a comparable increase for MREE to the 1:2 REE-mono-carboxylate stability constant pattern, conversely to the 1:1 REE-di-carboxylate pattern which shows an increase for HREE. This suggests that the formation of a $\mathrm{Yb}$ complex with two separate organic molecules, i.e. a cation bridge, might occur at high loading. Longer $\mathrm{Yb}-\mathrm{N}$ distances compared to $\mathrm{Yb}-\mathrm{O}$ previously observed for $\mathrm{N}$-containing ligands are also identified in the present complexes of Yb with IDA, NTA and EDTA by EXAFS. However, the low loading Yb-HA complex did not show this feature, suggesting a negligible amount of $\mathrm{N}$ in the first coordination sphere of $\mathrm{Yb}$. This suggests that, at low loading, $\mathrm{Yb}$ binds to O-containing groups of $\mathrm{HA}$ rather than $\mathrm{N}$ containing groups.

The experimental $\mathrm{L}_{\mathrm{III}}$-edge EXAFS study of $\mathrm{Sm}$ was more difficult than for $\mathrm{Yb}$. EXAFS spectra of the Sm samples could only be recorded up to $\mathrm{k}=10 \AA^{-1}$, compared to $\mathrm{k}=$ $13 \AA^{-1}$ for $\mathrm{Yb}$. The EXAFS analysis of the Sm-HA samples does not show clear differences between the structures of the Sm-HA complexes at high and low loading. These results cannot be compared directly with those of $\mathrm{Yb}$, and it cannot be concluded whether similar complexes are formed with HA. The REE-HA binding patterns at low loading increase for HREE, commonly seen in the 1:1 complexation pattern with multi-carboxylic chelate ligands, not necessarily exhibiting N-containing functional groups. According to the Pearson's (1963) 
hard and soft acid and base principle, cations exhibiting different chemical behavior might have different preferential strong binding sites in HA. This might have consequences for the prediction of HA complexation properties in natural waters, where competitive effects between various cations occur.

\section{ACKNOWLEDGMENTS}

The authors thank M. Le Coz-Bouhnik and M. Chorro for their help during the sample preparation and EXAFS records. Dr. S. Mullin is also acknowledged for post-editing the English style. This study was funded by French ANR, through the "Programme Jeunes Chercheurs": ANR -07-JCJC-0137, SURFREE.

\section{REFERENCES}

Ankudinov A. L., Ravel B., Rehr J. J. and Conradson S. D. (1998) Real-space multiple scattering calculation and interpretation of x-ray-absorption near-edge structure. Phys. Rev. B 58, 7565-7576.

Benedetti M. F., Milne C. J., Kinniburgh D. G., van Riemsdijk W. H. and Koopal L. K. (1995) Metal-ion binding to humic substances: application of the non-ideal competitive adsorption model. Environ. Sci. Technol. 29, 446-457.

Byrne R. H. and Li B. (1995) Comparative complexation behaviour of the rare earth elements. Geochim. Cosmochim. Acta 59, 4575-4589.

Carbonaro R. F., Atalay Y. B. and Di Toro D. M. (2011) Linear free energy relationships for metal-ligand complexation: Bidentate binding to negatively-charged oxygen donor atoms. Geochim. Cosmochim. Acta 75, 2499-2511.

Catrouillet C., Davranche M. Dia A., Bouhnik-Le Coz M., Marsac R., Pourret O. and Gruau G. (2014) Geochemical modeling of Fe(II) binding to humic and fulvic acids. Chem. Geol. 372, 109-118.

Choppin G. R., Thakur P. and Mathur J. N. (2006) Complexation thermodynamics and structural aspects of actinide-aminopolycarboxylates. Coord. Chem. Rev. 250, 936-947. 
Denecke M. A., Panak P. J., Burdet F., Weigl M., Geist A., Klenze R., Mazzanti M. and Gompper K. (2007) A comparative spectroscopic study of U(III)/Am(III) and Ln(III) complexed with N-donor ligands. C. R. Chimie 10, 872-882.

Ding S., Liang T., Zhang C., Huang Z., Xie Y. and Chen T. (2006) Fractionation mechanisms of rare earth elements (REEs) in hydroponic wheat: an application for metal accumulation by plants. Environ. Sci. Technol. 40, 2686-2691.

Furmanova N. G., Soboleva L. V., Khapaeva L. L. and Belov N. V. (1983) Crystal structure of Ytterbium formate dehydrate. Morphotropy in the lanthanide formate $\left(\operatorname{Ln}(\mathrm{HCOO})_{3}\right)$ dehydrate series. Kristallografiya 28(1), 62-66.

Gangloff S., Stille P., Pierret M.-C., Weber T. and Chabaux F. (2014) Characterization and evolution of dissolved organic matter in acidic forest soil and its impact on the mobility of major and trace elements (case of the Strengbach watershed). Geochim. Cosmochim. Acta 130, 21-41.

Henderson P. (1984) Rare Earth Element Geochemistry, P. Henderson, Editor, Elsevier, New York.

Hesterberg D., Chou J. W., Hutchison K. J. and Sayers D. E. (2001) Bonding of Hg(II) to reduced organic, sulfur in humic acid as affected by $\mathrm{S} / \mathrm{Hg}$ ratio. Environ. Sci. Technol. $35,2741-2745$.

Iglesias A., López R., Fiol S., Antelo J. M. and Arce F. (2003) Analysis of copper and calcium-fulvic acid complexation and competition effects. Wat. Res. 37, 3749-3755.

IUPAC (2001) IUPAC Stability Constants Database. Version 5.4, IUPAC and Academic 584 Software (acadsoft@bcs.org.uk).

Janicki R., Starynowicz P., and Mondry A. (2008) Complexes of $\mathrm{Yb}^{3+}$ with EDTA and CDTA - Molecular and electronic structure. Eur. J. Inorg. Chem. 19, 3075-3082.

Kinniburgh D. G., van Riemsdijk W. H., Koopal L. K., Borkovec M., Benedetti M. F. and Avena M. J. (1999) Ion binding to natural organic matter: competition, heterogeneity, stoichiometry and thermodynamic consistency. Colloid Surf. A 151, 147-166.

Kizler P., Kleebe H. J., Aldinger F. and Rühle M. (1997) Extended X-ray absorption fine structure (EXAFS) study of secondary phases in $\mathrm{Yb}_{2} \mathrm{O}_{3}$-doped $\mathrm{Si}_{3} \mathrm{~N}_{4}$ ceramics. J. Mater. Sci. 32, 369-374.

Kunhi Mouvenchery Y., Kučerík J., Diehl D. and Schaumann G. E. (2012) Cation-mediated cross-linking in natural organic matter: a review. Rev. Environ. Sci. Biotechnol. 11, 4154.

Manceau A. and Matynia A. (2010) The nature of $\mathrm{Cu}$ bonding to natural organic matter. Geochim. Cosmochim. Acta 74, 2556-2580.

Marang L., Eidner S., Kumke M. U., Benedetti M. F. and Reiller P. E. (2009) Spectroscopic characterization of the competitive binding of $\mathrm{Eu}$ (III), $\mathrm{Ca}$ (II), and $\mathrm{Cu}$ (II) to a sedimentary originated humic acid. Chem. Geol. 264, 154-161. 
Marang L., Reiller P. E., Eidner S., Kumke M. U. and Benedetti M. F. (2008) Combining spectroscopic and potentiometric approaches to characterize competitive binding to humic substances. Environ. Sci. Technol. 42, 5094-5098.

Marsac R., Davranche M., Gruau G. and Dia A. (2010) Metal loading effect on rare earth element binding to humic acid: Experimental and modelling evidence. Geochim. Cosmochim. Acta, 74, 1749-1761.

Marsac R., Davranche M., Gruau G., Dia A. and Bouhnik-Le Coz M. (2012). Aluminum competitive effect on rare earth elements binding to humic acid. Geochim. Cosmochim. Acta, 89, 1-9.

Marsac R., Davranche M., Gruau G., Bouhnik-Le Coz M. and Dia A. (2011) An improved description of the interactions between rare earth elements and humic acids by modeling: PHREEQC-Model VI coupling. Geochim. Cosmochim. Acta, 75, 5625-5637.

Marsac R., Davranche M., Gruau G., Bouhnik-Le Coz M. and Dia A. (2013) Iron competitive effect on REE binding to organic matter: implications with regards to REE patterns in waters. Chem. Geol., 342, 119-127.

Martell A.E. and Hancock R.D. (1996) Metal Complexes in Aqueous Solutions. New York: Kluwer.

Mathur J. N., Thakur P., Dodge C. J., Francis A. J. and Choppin G. R. (2006) Coordination modes in the formation of the ternary Am(III), $\mathrm{Cm}$ (III), and Eu(III) complexes with EDTA and NTA: TRLFS, 13C NMR, EXAFS and thermodynamics of the complexation. Inorg. Chem. 45, 8026-8035.

Milne C.J., Kinniburgh D.G., Van Riemsdijk W.H. and Tipping E. (2003) Generic NICADonnan model parameters for metal-ion binding by humic substances. Environ. Sci. Technol. 37, 958-971.

Montavon G., Hennig C., Janvier P. and Grambow B. (2006) Comparison of complexed species of Eu in alumina-bound and free polyacrylic acid: a spectroscopic study. J. Coll. Int. Sci. 300, 482-490.

Nakamura K., Kurisaki T., Wakita H. and Yamagushi T. (1995) Sodium Triaqua(ethylenediaminetetraacetato) lanthanate(III) Pentahydrate and the Isomorphous Neodymium(III) and Europium(III) Salts. Acta Cryst. C51, 1559-1563.

Narita H., Yaita T., Suzuki S., Takai K., Tachimori S. and Motohashi H. (2001) Structural studies of lanthanide(III) complexes with oxydiacetic acid and iminodiacetic acid in aqueous solution by EXAFS. J. Synchrotron Rad. 8, 672-673.

Neck V., Altmaier M., Rabung Th., Lützenkirchen J. and Fanghänel Th. (2009) Thermodynamics of trivalent actinides and neodymium in $\mathrm{NaCl}, \mathrm{MgCl}_{2}$, and $\mathrm{CaCl}_{2}$ solutions: Solubility, hydrolysis, and ternary Ca-M(III)-OH complexes. Pure Appl. Chem. 81, 1555-1568.

Newville M. (2001) IFEFFIT: interactive XAFS analysis and FEFF fitting, J. Synchrotron Rad., 322-324. 
Ngwenya T., Mosselmans J.F.W. Magennis M., Atkinson K.D., Tourney J., Olive V. and Ellam R.M. (2009) Macroscopic and spectroscopic analysis of lanthanide adsorption to bacteria cells. Geochim. Cosmochim. Acta 73, 3134-3147.

O’Day P. A., Rehr J. J., Zabinsky S. I. and Brown G. E. (1994) Extended X-ray absorption fine structure (EXAFS) analysis of disorder and multiple scattering in complex crystalline solids. J. Am. Chem. Soc. 116, 2938-2949.

Ohta A., Kagi H., Tsuno H., Nomura M. and Kawabe I. (2008) Influence of multi-electron excitation on EXAFS spectroscopy of trivalent rare earth ions and elucidation of change in hydration number through the series. Am. Mineral. 93, 1384-1392.

Ohta A., Kagi H., Nomura M., Tsuno H. and Kawabe I. (2009a) Coordination study of rare earth elements on $\mathrm{Fe}$ oxyhydroxide and $\mathrm{Mn}$ dioxides: Part I. Influence of a multielectron excitation on EXAFS analyses of La, Pr, Nd, and Sm. Am. Mineral., 94, 467475 .

Ohta A., Kagi H., Nomura M., Tsuno H. and Kawabe I. (2009b) Coordination study of rare earth elements on $\mathrm{Fe}$ oxyhydroxide and Mn dioxides: Part II. Correspondence of structural change to irregular variations of partitioning coefficients and tetrad effect variations appearing in interatomic distances. Am. Mineral., 94, 476-486.

Parkhurst D.L. and Appelo C.A.J. (1999) User's guide to PHREEQC (Version 2) - a computer program for speciation, batch reaction, one-dimensional transport and inverse geochemical calculation. Water-resources Investigation Report 99-4259, USGS, Denver, Colorado, p. 312.

Pearson R. G. (1963) Hard and Soft Acids and Bases. J. Am. Chem. Soc. (85), 3533.

Pourret O., Davranche M., Gruau G. and Dia A. (2007) Rare earth complexation by humic acid. Chem. Geol., 243, 128-141.

Rabung T. and Geckeis H. (2008). Influence of $\mathrm{pH}$ and metal ion loading on the Cm(III) humate complexation: a time resolved laser fluorescence spectroscopy study, Radiochim. Acta 97, 265-271.

Ravel B. and Newville M. (2005) ATHENA; ARTEMIS; HEPHAESTUS: data analysis for X-ray absorption spectroscopy using IFEFFIT. J. Synchrotron Rad. 12, 537-541.

Ritchie J.D. and Perdue E.M. (2003) Proton-binding study of standard and reference fulvic acids, humic acids, and natural organic matter. Geochim. Cosmochim. Acta 67, 85-96.

Sachs S., Schmeide K., Reich T., Brendler V., Heise K. H. and Bernhard G. (2005) EXAFS study on the neptunium(V) complexation by various humic acids under neutral $\mathrm{pH}$ conditions. Radiochim. Acta 93, 17-25.

Schmeide K., Sachs S., Bubner M., Reich T., Heise K. H. and Bernhard G. (2003) Interaction of uranium(VI) with various modified and unmodified natural and synthetic humic substances studied by EXAFS and FTIR spectroscopy. Inorg. Chim. Acta 351, 133-140.

Smith R. M., Martell A. E. and Motekaitis R. J. (1985) Prediction of stability constants. I. protonation constants of carboxylates and formation constants of their complexes with class A metal ions. Inorg. Chim. Acta 99, 207-216. 
Schijf J. and Byrne R. H. (2001) Stability constants for mono- and dioxalato-complexes of Y and the REE, potentially important species in groundwaters and surface freshwaters. Geochim. Cosmochim. Acta 65, 1037-1046.

Sonke J.E. and Salters V.J.M. (2006) Lanthanide-humic substances complexation. I. Experimental evidence for a lanthanide contraction effect. Geochim. Cosmochim. Acta 70, 1495-1506.

Sutton R. and Sposito G. (2005) Molecular Structure in Soil Humic Substances: The New View. Environ. Sci. Technol. 39(23), 9009-9015.

Takahashi Y., Yamamoto M., Yamamoto Y. and Tanaka K. (2010) EXAFS study on the cause of enrichment of heavy REEs on bacterial cell surfaces. Geochim. Cosmochim. Acta 74, 5443-5462.

Tang J. and Johannesson K. H. (2003) Speciation of rare earth elements in natural terrestrial waters: assessing the role of dissolved organic matter from the modeling approach. Geochim. Cosmochim. Acta 67, 2321-2339.

Tipping E. (1998) Humic ion-binding model VI: an improved description of the interactions of protons and metal ions with humic substances. Aquat. Geochem. 4, 3-48.

Tipping E., Lofts S. and Sonke J. (2011) Humic ion-binding Model VII: a revised parameterisation of cation-binding by humic substances. Environ. Chem. 8, 225-235.

Wang D., Wang C., Zhao G., Wei Z., Tao Y. and Liang X. (2001) Composition, characteristic and activity of rare earth element bound polysaccharide from tea. Biosci. Biotechnol. Biochem. 65, 1987-1992.

Zotov A. V., Tagirov B. R., Diakonov I. I. and Ragnarsdottir K. V. (2002) A potentiometric study of Eu3 complexation with acetate ligand from 25 to $170^{\circ} \mathrm{C}$ at Psat. Geochim. Cosmochim. Acta 66(20), 3599-3613. 
Table 1. Fitting results for $\mathrm{Yb} \mathrm{L}_{\mathrm{II}}$-edge EXAFS spectra of $\mathrm{Yb}-\mathrm{HA}$ complexes and of standard organic molecules $\mathrm{Yb}$ complexes. Selected crystallographic data for $\mathrm{Yb}$-EDTA and $\mathrm{Yb}$-(formate) ${ }_{3}$ are also reported for comparison with standard deviation under brackets. $\mathrm{CN}$ : coordination number, $\mathrm{R}$ : interatomic distance, $\Delta \mathrm{E}_{0}$ : threshold energy shift, $\sigma^{2}$ : Debye-Waller factor. Reported errors are determined by the fitting procedure but errors on $\mathrm{CN}, \mathrm{R}$ and $\sigma^{2}$ parameter values are generally $\pm 20 \%, \pm 0.02 \AA$ and $\pm 20 \%$ in the best case (O'Day et al., 1994). The average bond distance in $\mathrm{Yb}$ first shell is also given in italic.

\begin{tabular}{|c|c|c|c|c|c|c|}
\hline & Path & $\mathbf{R}(\mathbf{A})$ & $\mathbf{C N}$ & $\Delta \mathrm{E}_{0}(\mathrm{eV})$ & $\sigma^{2} \times 10^{3}\left(\AA^{2}\right)$ & $\begin{array}{c}\text { Reduced- } \\
\chi^{2}\end{array}$ \\
\hline Yb-EDTA & $\mathrm{Yb}-\mathrm{O}$ & $2.28(0.04)$ & 6 & & & \\
\hline \multirow{4}{*}{ Janicki et al. (2008) } & $\mathrm{Yb}-\mathrm{N}$ & $2.58(0.01)$ & 2 & & & \\
\hline & $\mathrm{Yb}-\mathrm{C}$ & $3.28(0.10)$ & 10 & & & \\
\hline & $\mathrm{Yb}-\mathrm{O} / \mathrm{C}-\mathrm{O}_{\mathrm{u}}(\mathrm{MS})$ & $4.39(0.03)$ & 8 & & & \\
\hline & Yb-first shell & 2.34 & 8 & & & \\
\hline \multirow[t]{5}{*}{ Yb-EDTA } & $\mathrm{Yb}-\mathrm{O}$ & $2.29 \pm 0.01$ & $6.5 \pm 0.8$ & $5.1 \pm 0.5$ & $7 \pm 1^{\mathrm{a}}$ & 938 \\
\hline & $\mathrm{Yb}-\mathrm{N}$ & $2.50 \pm 0.03$ & $2.3 \pm 0.4$ & & $7^{\mathrm{a}}$ & \\
\hline & $\mathrm{Yb}-\mathrm{C}$ & $3.23 \pm 0.01$ & $8.3 \pm 2.0$ & & $12 \pm 3$ & \\
\hline & $\mathrm{Yb}-\mathrm{O} / \mathrm{C}-\mathrm{O}_{\mathrm{u}}(\mathrm{MS})$ & $4.44 \pm 0.01$ & $10.3 \pm 2.6$ & & $6 \pm 2$ & \\
\hline & $Y b$-first shell & 2.34 & 8.8 & & & \\
\hline \multirow[t]{5}{*}{ Yb-NTA } & Yb-O & $2.31 \pm 0.01$ & $6.8 \pm 1.0$ & $5.3 \pm 0.5$ & $6 \pm 1^{a}$ & 516 \\
\hline & Yb-N & $2.48 \pm 0.03$ & $2.5 \pm 0.5$ & & $6^{\mathrm{a}}$ & \\
\hline & $\mathrm{Yb}-\mathrm{C}$ & $3.23 \pm 0.02$ & $6.5 \pm 2.4$ & & $16 \pm 5$ & \\
\hline & $\mathrm{Yb}-\mathrm{O} / \mathrm{C}-\mathrm{O}_{\mathrm{u}}(\mathrm{MS})$ & $4.44 \pm 0.01$ & $5.9 \pm 2.1$ & & $6 \pm 3$ & \\
\hline & Yb-first shell & 2.36 & 9.3 & & & \\
\hline \multirow[t]{5}{*}{ Yb-IDA } & $\mathrm{Yb}-\mathrm{O}$ & $2.31 \pm 0.01$ & $7.3 \pm 0.9$ & $6.1 \pm 0.6$ & $8 \pm 1^{a}$ & 276 \\
\hline & Yb-N & $2.51 \pm 0.03$ & $2.5 \pm 0.4$ & & $8^{\mathrm{a}}$ & \\
\hline & $\mathrm{Yb}-\mathrm{C}$ & $3.30 \pm 0.03$ & $4.2 \pm 2.5$ & & $20 \pm 1$ & \\
\hline & $\mathrm{Yb}-\mathrm{O} / \mathrm{C}-\mathrm{O}_{\mathrm{u}}(\mathrm{MS})$ & $4.48 \pm 0.02$ & $3.3 \pm 0.8$ & & $6^{\mathrm{b}}$ & \\
\hline & $Y b$-first shell & 2.36 & 9.8 & & & \\
\hline \multirow[t]{3}{*}{ Yb-L7 } & $\mathrm{Yb}-\mathrm{O}$ & $2.32 \pm 0.01$ & $9.0 \pm 0.3$ & $5.3 \pm 0.3$ & $11 \pm 1$ & 218 \\
\hline & $\mathrm{Yb}-\mathrm{C}$ & $3.26 \pm 0.01$ & $2.0 \pm 0.8$ & & $7 \pm 4$ & \\
\hline & $\mathrm{Yb}-\mathrm{O} / \mathrm{C}-\mathrm{O}_{\mathrm{u}}(\mathrm{MS})$ & $4.49 \pm 0.01$ & $4.8 \pm 1.9$ & & $7 \pm 3$ & \\
\hline \multirow[t]{3}{*}{$\mathrm{Yb}-\mathrm{H} 7$} & $\mathrm{Yb}-\mathrm{O}$ & $2.29 \pm 0.02$ & $6.4 \pm 1.2$ & $7.4 \pm 0.8$ & $9 \pm 2^{\mathrm{a}}$ & 878 \\
\hline & Yb-O & $2.43 \pm 0.03$ & $3.1 \pm 0.7$ & & $9^{\mathrm{a}}$ & \\
\hline & Yb-first shell & 2.35 & 7.4 & & & \\
\hline \multirow[t]{4}{*}{ Yb-carboxylic resin } & $\mathrm{Yb}-\mathrm{O}$ & $2.31 \pm 0.02$ & $4.3 \pm 1.6$ & $10.4 \pm 2.0$ & $4 \pm 2^{a}$ & 281 \\
\hline & $\mathrm{Yb}-\mathrm{O}$ & $2.44 \pm 0.03$ & $2.9 \pm 0.8$ & & $4^{\mathrm{a}}$ & \\
\hline & $\mathrm{Yb}-\mathrm{C}$ & $2.75 \pm 0.03$ & $1.4 \pm 0.8$ & & $4^{\mathrm{a}}$ & \\
\hline & $Y b$-first shell & 2.36 & 7.2 & & & \\
\hline $\mathrm{Yb}(\text { formate })_{3}(\mathrm{XRD})$ & $\mathrm{Yb}-\mathrm{O} 1$ & $2.27(0.03)$ & 4 & & & \\
\hline \multirow[t]{4}{*}{ Furmanova et al. (1983) } & $\mathrm{Yb}-\mathrm{O} 2$ & $2.40(0.02)$ & 4 & & & \\
\hline & $\mathrm{Yb}-\mathrm{C}_{\text {mono }}$ & 3.23 & 1 & & & \\
\hline & $\mathrm{Yb}-\mathrm{C}_{\mathrm{bi}}$ & $2.77(0.02)$ & 2 & & & \\
\hline & $Y b$-first shell & $2.33(0.08)$ & 8 & & & \\
\hline
\end{tabular}

$\Delta \mathrm{E}_{0}$ was set equal for all paths.

(a) $\sigma^{2}$ values were constrained equal during the fit.

(b) set equal to the value determined for EDTA and NTA. 
Table 2. Fitting results for $\mathrm{Sm} \mathrm{L}_{\mathrm{III}}$-edge EXAFS spectra of Sm-HA complexes and of standard organic molecules Sm complexes. Selected crystallographic data for Eu-EDTA (Nakamura et al., 1995) are also reported for comparison with standard deviation under brackets. $\mathrm{CN}$ : coordination number, $\mathrm{R}$ : interatomic distance, $\Delta \mathrm{E}_{0}$ : threshold energy shift, $\sigma^{2}$ : Debye-Waller factor. Reported errors are determined by the fitting procedure but errors on $\mathrm{CN}, \mathrm{R}$ and $\sigma^{2}$ parameter values are generally $\pm 20 \%, \pm 0.02 \AA$ and $\pm 20 \%$ in the best case (O'Day et al., 1994).

\begin{tabular}{|c|c|c|c|c|c|c|}
\hline & Shell & $\mathbf{R}(\AA)$ & $\mathbf{C N}$ & $\Delta E_{0}(e V)$ & $\sigma^{2} \times 10^{3}\left(\AA^{2}\right)$ & Reduced- $\chi^{2}$ \\
\hline Eu-EDTA (XRD) & Eu-O & $2.45(0.06)$ & 7 & & & \\
\hline \multirow[t]{3}{*}{ Nakamura et al. (1995) } & Eu-N & $2.67(0.03)$ & 2 & & & \\
\hline & $\mathrm{Eu}-\mathrm{C}$ & $3.40(0.08)$ & 10 & & & \\
\hline & Eu-first shell & $2.50(0.11)$ & 9 & & & \\
\hline \multirow[t]{2}{*}{ Sm-EDTA } & $\mathrm{Sm}-\mathrm{O} / \mathrm{N}$ & $2.44 \pm 0.01$ & $10.2 \pm 0.9$ & $10.1 \pm 0.6$ & $14 \pm 1^{\mathrm{a}}$ & 8490 \\
\hline & $\mathrm{Sm}-\mathrm{C}$ & $3.37 \pm 0.02$ & $6.3 \pm 1.4$ & & $14^{\mathrm{a}}$ & \\
\hline \multirow[t]{2}{*}{ Sm-NTA } & $\mathrm{Sm}-\mathrm{O} / \mathrm{N}$ & $2.44 \pm 0.01$ & $8.8 \pm 0.7$ & $6.4 \pm 0.8$ & $7 \pm 1^{\mathrm{a}}$ & 4353 \\
\hline & $\mathrm{Sm}-\mathrm{C}$ & $3.35 \pm 0.05$ & $2.2 \pm 1.3$ & & $7^{\mathrm{a}}$ & \\
\hline Sm-IDA & $\mathrm{Sm}-\mathrm{O} / \mathrm{N}$ & $2.44 \pm 0.01$ & $9.2 \pm 0.7$ & $6.5 \pm 0.7$ & $9 \pm 1$ & 190 \\
\hline Sm-L7 & $\mathrm{Sm}-\mathrm{O} / \mathrm{N}$ & $2.43 \pm 0.01$ & $9.2 \pm 0.4$ & $8.4 \pm 0.4$ & $10 \pm 1$ & 873 \\
\hline $\mathrm{Sm}-\mathrm{H} 7$ & $\mathrm{Sm}-\mathrm{O} / \mathrm{N}$ & $2.44 \pm 0.01$ & $11.5 \pm 2.3$ & $2.3 \pm 1.6$ & $13 \pm 2$ & 2422 \\
\hline $\mathrm{Sm}-\mathrm{COOH}$ & $\mathrm{Sm}-\mathrm{O}$ & $2.46 \pm 0.01$ & $9.5 \pm 0.8$ & $9.2 \pm 0.8$ & $9 \pm 1$ & 87 \\
\hline
\end{tabular}

$\Delta \mathrm{E}_{0}$ was set equal for all paths.

(a) $\sigma^{2}$ values were constrained equal during the fit. 

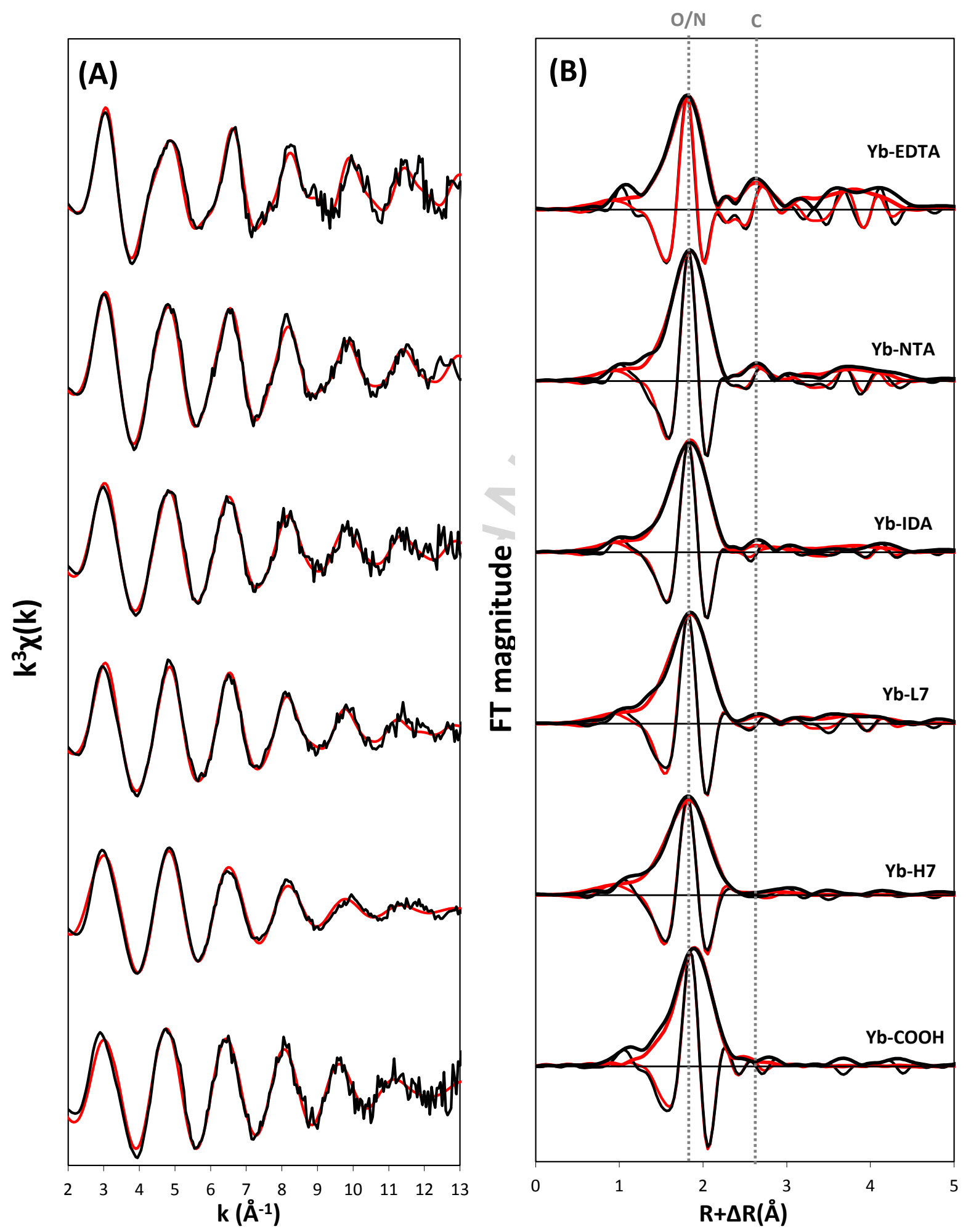

Figure 1. (A) Normalized $\mathrm{k}^{3}$-weighted EXAFS spectra of the $\mathrm{Yb}-\mathrm{HA}$ and $\mathrm{Yb}$-standard organic ligand (where "Yb-COOH" refers to the carboxylic-grafted resin) and (B) their corresponding Fourier Transform magnitude and imaginary part. $\mathrm{Yb}-\mathrm{H} 7$ and - $\mathrm{L} 7$ represent the $\mathrm{Yb}-\mathrm{HA}$ complexes at high and low $\mathrm{Yb}$ loadings at $\mathrm{pH} 7$, respectively. Red curves represent the fits of the experimental data with the parameters listed in Table 1. 

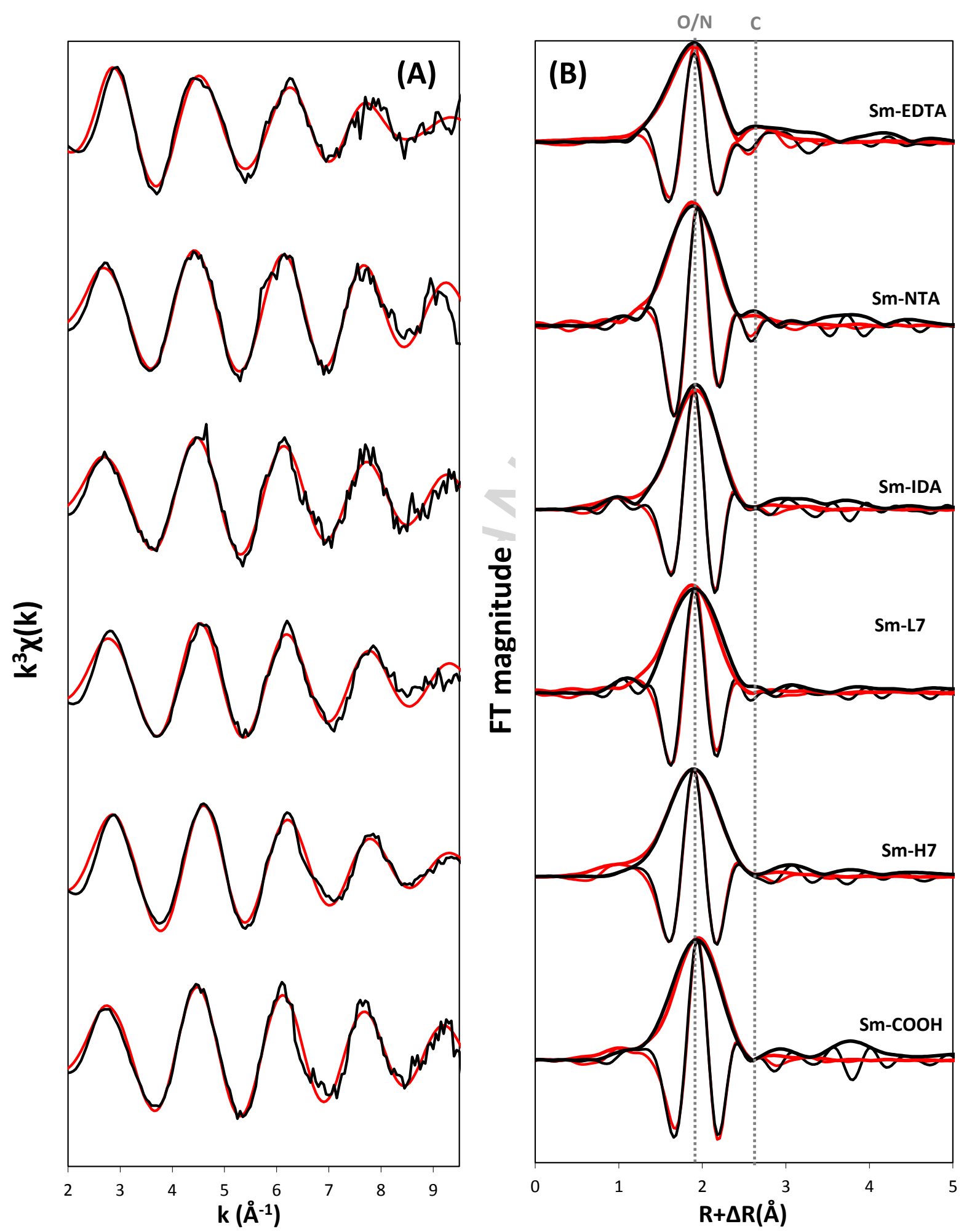

Figure 2. (A) Normalized $\mathrm{k}^{3}$-weighted EXAFS spectra of the Sm-HA and Sm-standard organic ligand (where "Sm-COOH" refers to the carboxylic-grafted resin) and (B) their corresponding Fourier Transform magnitude and imaginary part. Sm-H7 and -L7 represent the Sm-HA complexes at high and low Sm loadings at pH 7, respectively. Red curves represent the fits of the experimental data with the parameters listed in Table 2. 


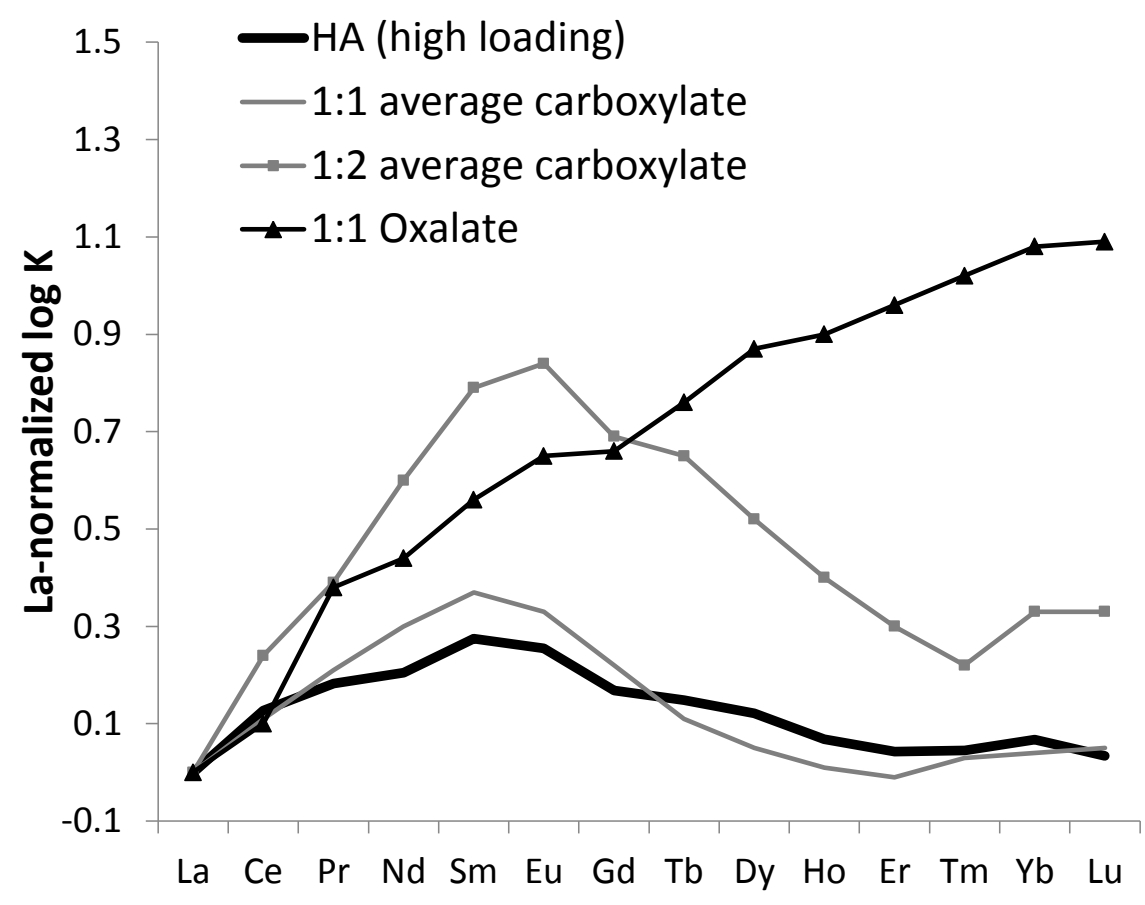

Figure 3. La-normalized REE-HA complexation pattern at high metal loading (Model VI) compared to an average value for 1:1 and 1:2 REE-small carboxylates (Smith et al., 1985), 1:1 Patterns for the REE-oxalate (Schijf and Byrne, 2001) complexation constants. At high metal loading, REE mainly form complexes with biligand HA sites according to Model VI. 


\section{Highlights:}

- At high and low metal loading, the structure of Sm and Yb complexes with humic acid are determined by EXAFS spectroscopy.

- Model VII predicts that $\mathrm{Yb}$ and $\mathrm{Sm}$ tend to bind to strong humic $\mathrm{N}$-containing groups at low metal loading.

- At low metal loading the presence of $\mathrm{N}$ could not be demonstrated, in contrast with reference complexes with IDA, NTA or EDTA.

- At high metal loading, carboxylic humic groups are found to be coordinated in bidentate mode.

- The results are discussed in the context of cation competition and supramolecular structure of metal-humate complexes. 